\title{
Modeling and optimal control of an energy-efficient hybrid solar air conditioning system
}

\author{
Q.P. Ha *, V. Vakiloroaya \\ Faculty of Engineering and Information Technology, University of Technology, Sydney, PO Box 123 Broadway, NSW 2007, Australia
}

\section{A R T I C L E I N F O}

\section{Article history:}

Accepted 18 June 2014

Available online xxxx

\section{Keywords:}

Solar-assisted air-conditioner

Sub-cooling

Refrigerant mass flow rate

Air flow rate

Optimal control

\begin{abstract}
A B S T R A C T
The paper addresses the modeling and optimal control problem of a new hybrid solar-assisted air conditioning system developed for performance enhancement and energy efficiency improvement. To regulate the mass flow rate of the refrigerant vapor passing through a water storage tank for increasing the refrigerant's subcooling process at partial loads, we propose a new discharge bypass line together with an inline solenoid valve, installed after the compressor. In addition, to control the air flow rate, a variable speed drive is coupled with the condenser fan. For the control purpose, a lumped parameter model is first developed to describe the system dynamics in an explicit input-output relationship; then, a linear optimal control scheme is applied for the system's multivariable control. The system has been fully-instrumented to examine its performance under different operation conditions. The system model is then validated by extensive experimental tests. Based on the obtained dynamic model, an optimal controller is designed to minimize a quadratic cost function. Numerical algorithms, implemented in a simulation tool, are then employed to predict the energy performance of the system under transient loads. The experimental results obtained from implementation with PLC demonstrate that the newly-developed system can deliver higher system efficiency owing to amelioration of the refrigeration effect in the direct expansion evaporator and adjustment of its air flow rate. The development is thus promising for improvement of energy efficiency, enhancement of the system performance while fulfilling the cooling demand.
\end{abstract}

(c) 2014 Elsevier B.V. All rights reserved.

\section{Introduction}

Heating, ventilating and air conditioning (HVAC) systems consume significant amounts of electricity. Among energy consumption of commercial and residential buildings, HVAC systems account for over $50 \%$ of the total energy usage [1]. They also lead to the reduction of the valuable fossil fuel sources and production of the greenhouse gases which are known to cause ozone layer depletion [2]. In addition, a recent energy overview predicts that energy use in the built environment will grow by $34 \%$ in the next 20 years at an average rate of $1.5 \%$ [3]. However, it is noted that the major part of the energy usage still comes from fossil fuels [4]. Therefore, the overall attainable reduction in energy consumption and enhancement of human comfort in buildings are dependent on the performance of HVAC systems. The possibility of cooling via the use of renewable energy has been intriguing on how to combine air conditioning systems with free energy sources so as to reduce their power consumption. In recent years, due to world energy shortage, different types of cooling technologies in combination with solar thermal energy have been explored. For this, most efficient among the sources is perhaps the solar thermal energy. Solar energy is clean and accessible all over the world, especially feasible in regions with high solar radiation.

\footnotetext{
* Corresponding author.

E-mail address: quang.ha@uts.edu.au (Q.P. Ha).
}

It has been estimated of around 35-45\% reduction in the total system cost for solar thermal cooling by 2030 [5]. Technically, solar energy is applied to air conditioning systems either by photovoltaic panels or heat driven sorption systems. Applying solar energy on various types of HVAC systems has proven its potential for energy usage reduction. However, solar radiation is a highly time-dependent energy source and it does not necessarily match with the building demand. This problem can be addressed by regulating the storage and release of thermal energy according to the building load. Therefore, an appropriate control method should be employed by solar-assisted HVAC systems to adjust the transient building demand with the stored solar thermal energy. In construction automation, building energy management and the necessity to reduce overall energy consumption are becoming an increasingly important topic, given with highly dynamic environments in association with frequently varying conditions of the building setting and its occupancy [6]. For air conditioned buildings, an important problem is energy optimization, for example using a reliable model for predicting the whole building heat and moisture transfer [7]. In the building and energy context, the application of modeling and control engineering has proved to be promising [8].

Among different types of HVAC systems, the direct expansion (DX) wall-mounted air-conditioner with a vapor compression cycle is commonly-used. This system that uses energy obtained by fossil fuels can output two to six times thermal energy through absorption from 
renewable energy sources [9]. However, air-cooled air conditioning systems are less energy efficient than water-cooled air conditioning system [10] and thus finding novel ways to reduce its energy consumption without compromising comfort and indoor air quality is an ongoing research challenge. A large number of theoretical and experimental investigations on solar-assisted HVAC systems have been reported. The feasibility of using different photovoltaic systems for supplying the electricity of a window-type air conditioner was investigated in [11], where better performance in meeting the air conditioner requirements was obtained from the hybrid grid photovoltaic (PV) wind system. A solar electric-vapor compression refrigeration system and investigated its performance for different evaporating temperature [12], but the system required a large photovoltaic panel area when decreasing evaporative temperature. To balance the inconsistency between solar radiation and cooling load, a solar-powered absorption refrigeration system was presented in [13], using the mass energy transformation and storage technology to obtain a system COP of 0.7525 for the air-cooled condenser, and 0.7555 for the water-cooled condenser. The performance of a condenser heat recovery with a PV/T air heating collector to regenerate desiccant for reducing energy use of an air conditioning room was investigated by [14], who indicated via experimental test and dynamic simulation that electricity of about $6 \%$ of the daily total solar radiation can be gained from the PV/T collector. The proposed system was able to save about $18 \%$ of the total energy use of the air conditioner. A dynamic model for investigating the performance of a solar-driven ejector refrigeration plant was presented in [15] for an office building, wherein a conservation of more than $75 \%$ of electricity was shown in comparison to a traditional compressor based air conditioner. A solar driven twostage rotary desiccant cooling plant was combined with a vapor compression air conditioning system in [16], where experimental investigations showed that the solar driven desiccant cooling system can handle about $33 \%$ of the cooling load which means a $34 \%$ reduction in power consumption compared with a vapor compression system. Solarassisted heat pump drying systems have also been shown as capable of improving coefficient of performance (COP) and thermal efficiency while reducing energy consumption to enhance the quality of agricultural and marine products where low temperature and well-controlled drying conditions are required [17].

To date, not much research has been devoted to the influence of solar vacuum collectors installed after the compressor on the energy performance of vapor compression air conditioning systems. In existing solar-assisted air conditioner, the compressor is sized solely on the discharge pressure requirement, with additional heat input to the refrigerant being provided by solar collectors and their associated hot water storage tank. In this paper, in line with the modeling and control framework of achieving higher performance of solar air-conditioners via closed-loop control [18], the system has been configured to increase the sub-cooling process at partial loads by regulating the mass flow rate of the refrigerant in the hot water tank as well as the air flow rate at the condenser outlet as control variables. Because building cooling load varies with the time of the day, an HVAC system could be equipped with an effective controller to reduce the energy consumption by keeping the process variables to their optimal set-point required. This has motivated the work presented in this paper, to reconfigure the system developed in [19] with a refined model validated from experiments, and to design and implement an optimal regulator for its closed-loop multivariable control. The new hybrid solar-assisted system features a discharge bypass line, an inline controlled solenoid valve, a condenser fan with variable speed drive, and a programmable logic controller for closed-loop control of two outputs, namely the temperatures of the refrigerant leaving the condenser and leaving the compressor, respectively. Thus, the contribution of this paper rests with (i) a new configuration of the solar-assisted DX air-conditioner with controllable flow rates of the refrigerant passing through the hot water tank and of the air from the condenser outlet by varying its speed, (ii) a comprehensive model of the reconfigured system, and (iii) a multi-input multi-output control scheme based on the linear quadratic regulator (LQR) technique for optimal control of the system dynamics.

The objective of this study is thus to describe the new configuration of the hybrid solar-assisted air conditioning system, to derive its dynamical model and develop an optimal controller, and to report on its system performance with regard to the ultimate goal of reduction of the energy consumption. In our system, as the solar collector is installed after the compressor to reduce the compressor work, it increases the refrigerant temperature leaving the condenser because of the additional heat added before the condenser especially in partial load conditions. This results in some reduction of the system's COP. Therefore, a proper control strategy should lower the refrigerant temperature leaving the condenser and, in turn, increase the overall COP [20]. To achieve this, a novel configuration including a by-pass line together with a currentcontrolled three-way proportional valve has been inserted in the discharge line after the compressor in order to control the refrigerant temperature [21]. Furthermore, a variable speed drive (VSD) is also connected to the condenser fan to adjust the condenser fan speed in accordance to the closing and opening of the by-pass valve. Our aims include the regulation of the refrigerant flow rate in order to enhance the subcool temperature for various cooling loads and ambient conditions and also the control of the air flow from the condenser fan so as to reduce the refrigerant temperature entering the evaporator, with the ultimate goal to enhance the system refrigeration effect overall and thereby its coefficient of performance. Mathematical models and experimental data are implemented on a transient simulation tool, TRNSYS 16 [22], to predict performance of the system. Results show that the new implemented mechanical design together with its proposed control system can yield to higher sub-cool temperature after the condenser which can increase further the overall coefficient of performance up to $9 \%$.

This paper is organized as follows. After the introduction, the proposed configuration of the system is described in Section 2. A dynamic model of the system is derived in Section 3, followed by Section 4 on its optimal control design. The results and discussion are included in Section 5. Finally a conclusion is drawn in Section 6.

\section{Proposed configuration}

\subsection{System description}

A single stage vapor compression solar air-conditioner consists of six major components: a compressor, a condenser, an expansion device, an evaporator, a solar vacuum collector and a solar storage tank. The schematic diagram of the arrangement is shown in Fig. 1. The cycle starts with a mixture of liquid and vapor refrigerant entering the evaporator (point 1). The heat from the warm air is absorbed by an evaporator coil. During this process, the state of the refrigerant is changed from liquid to gas and becomes superheated at the evaporator exit. The superheat vapor enters the compressor (point 2), where the increasing pressure causes to raise the refrigerant temperature. A vacuum solar panel installed after the compressor uses the sun radiation to heat up the water. An insulated water storage tank is connected to the vacuum solar collector to maintain the water temperature. The refrigerant from the compressor goes through the copper coil inside the tank and undertakes a heat exchange (point 3 ). The vacuum solar collector reheats the refrigerant to reach the necessary superheat temperature. At this point, the high pressure superheated gas travels to the condenser for heat rejection to the ambient air (point 4). A further reduction in temperature happens in the condenser and causes it to de-superheat, and thus, the refrigerant liquid is sub-cooled as it enters the capillary tube.

Since a rotary scroll compressor is used in this plant, when the desired temperature inside the building is reached, the compressor will be turned off and block the return of the refrigerant back to the suction line via an inline two-way valve, installed at the condenser inlet after the storage tank. In this case, the condenser inlet valve is closed and thus the temperature and pressure of the refrigerant inside the heat 


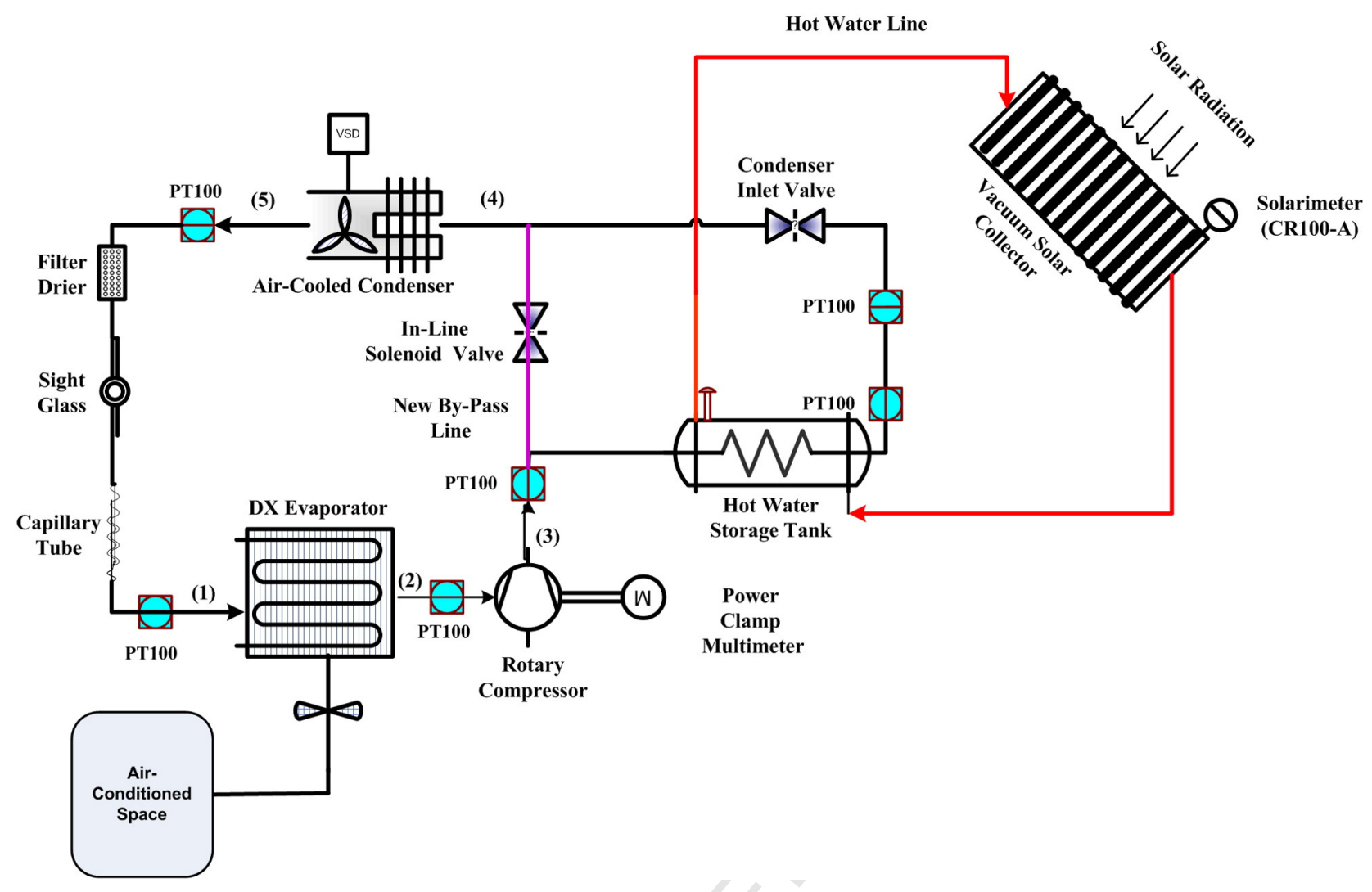

Fig. 1. New configuration of a hybrid solar assisted air conditioner with two control variables.

exchanger of the hot water storage tank are increased. This will increase slightly the refrigerant pressure which reduces the discharge pressure of the compressor when restarting. The additional pressure obtained from the hot water storage tank decreases the compressor pressure ratio when it turns on again, i.e. the compressor works with a less discharge pressure as compared to a conventional air conditioning system. On the other hand, the temperature of the refrigerant entering the condenser is raised owing to the heat from the water storage tank while the compressor is running, which may reduce the sub-cool temperature and decrease the system COP. Taking this into account, the proposed configuration consists of a new discharge by-pass line together with its in-line solenoid valve, installed after the compressor to direct the refrigerant mass flow either via the storage tank or the by-pass line according to the difference between the storage tank's water temperature and the refrigerant temperature leaving the compressor [21]. In other words, when the refrigerant temperature leaving the compressor is less than the storage tank's water temperature, the by-pass valve opens, allowing the refrigerant to go through the new by-pass line directly to the condenser while its inlet valve is closed. On the contrary, when the refrigerant temperature leaving the compressor is higher than the water temperature, the by-pass valve closes, directing the refrigerant to go through the water storage tank while the condenser inlet valve is opened. In addition, when the compressor turns off, both valves are closed. Since the nature of building cooling loads and ambient conditions is highly transient, the solenoid by-pass valve will be controlled to act synchronously with the compressor inlet valve to continuously monitor the refrigerant direction entering the condenser under all conditions.

Furthermore, to allow for control of the air flow rate at the condenser outlet (point 5) in synchronization with the inline valve closing and opening, a current-driven variable speed drive is coupled with the condenser fan to adjust the condenser fan speed and thus enhance the subcooling after the condenser. This, in turn, also reduces the refrigerant temperature entering the evaporator. Overall, the two control variables contribute to enhance the system refrigeration effect and thereby the coefficient of performance of the proposed solar air-conditioning system.

\subsection{Experimental set-up}

Experimental work was carried out using a newly-developed solarassisted DX hybrid air conditioner, as shown in Fig. 2. The system is extensively equipped with sensors and data logging device as a demonstrator for green automation technologies for building HVAC [18].

The experimental set-up is mainly composed of two parts: an airconditioned room served by the direct expansion evaporator unit, and the condensing unit combined with a solar vacuum collector. The nominal output cooling capacity of the air-conditioner is $5.7 \mathrm{~kW}$. The plant has one scroll hermetic compressor using refrigerant R410A as a working fluid. The amount of charged refrigerant into the system is $1.8 \mathrm{~kg}$. The design air flow rate of the evaporator fan is $850 \mathrm{~m}^{3} / \mathrm{h}$. The condenser in the plant is an air-cooled tube and uses a coated fin tube. The design air flow rate of the condenser axial fan is $2500 \mathrm{~m}^{3} / \mathrm{h}$ and its rated power input is $50 \mathrm{~W}$. The collector is integrated at a tilted angle of $5^{\circ}$ and oriented towards north (for usage in the southern hemisphere). The solar collector is made of 11 evacuated tubes with length of $55 \mathrm{~cm}$ and diameter of $10 \mathrm{~cm}$. The solar collector is equipped with an 18-liter horizontal cylindrical storage tank, insulated by polyurethane of $55 \mathrm{~mm}$ thickness. This system has been fully-instrumented to facilitate a number of tests under different operation conditions [23]. Field tests were run continuously to monitor the system performance at various weather conditions for two weeks. Day-long tests were carried out for 24 hours and all measured data was monitored in 20-minute intervals. All measurements were then computerized so that all the measured data could be recorded for subsequent analysis. 


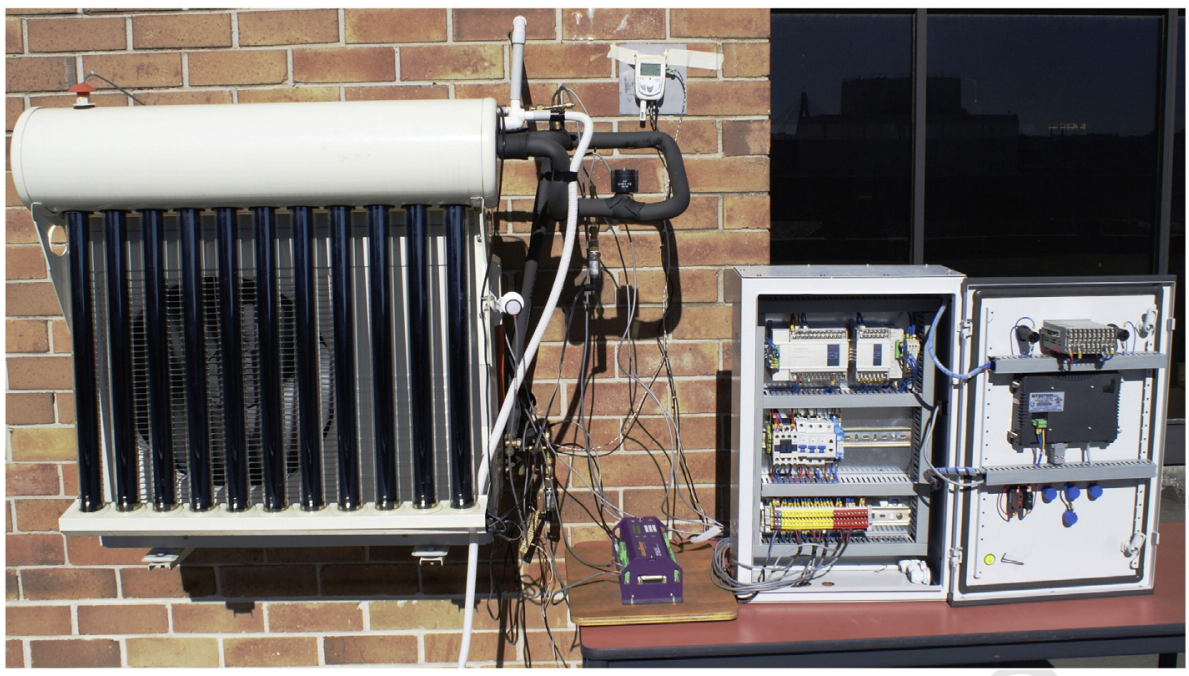

Fig. 2. Experimental hybrid solar-assisted air conditioner with its PLC implementation.

\section{System modeling}

This section describes the mathematical model of the system components by applying the energy and mass balance principles. The proposed configuration for the system can be dynamically characterized by the refrigerant temperatures leaving the compressor, leaving the condenser and leaving the storage tank with the control variables being the refrigerant mass flow rate and condenser air flow rate.

By denoting $T_{a m b}, T_{r l c}, T_{\text {comp }}$ and $T_{w s t}$, respectively as the ambient temperature and the temperatures of refrigerant leaving the condenser, compressor and water storage tank; $T_{w}, T_{\text {con }}, T_{i n}$ and $T_{\text {sup }}$ respectively as the water temperature inside the storage tank, the condenser temperature, the room temperature, and the evaporator outlet superheat temperature; the energy balance principle for the condenser coil gives:

$$
\begin{aligned}
\frac{d T_{r l c}}{d t}= & \frac{d T_{a m b}}{d t}\left(1-\exp \left(-\frac{A_{c o n} K_{c o n}}{\dot{m}_{r} C_{p, r}}\right)\right) \\
& +\left[\frac{\dot{m}_{r e l}}{\dot{m}_{r}} \frac{d T_{\text {comp }}}{d t}+\frac{\dot{m}_{r e s}}{\dot{m}_{r}} \frac{d T_{\text {wst }}}{d t}\right] \exp \left(-\frac{A_{\text {con }} K_{\text {con }}}{\dot{m}_{r} C_{p, r}}\right)+\beta \dot{m}_{a},
\end{aligned}
$$

where $A_{\text {con }}$ and $K_{\text {con }}$ are respectively the condenser coil area and heat transfer coefficient, $\dot{m}_{r}$ and $C_{p, r}$ are respectively the refrigerant mass flow rate and heat capacity, $\dot{m}_{\text {rel }}$ and $\dot{m}_{\text {res }}$ are respectively the refrigerant flow rate entering the by-pass line and storage tank, $\dot{m}_{a}$ is the condenser air flow rate, and where parameter $\beta$ is defined as:

$\beta=\frac{Q_{\text {con }}}{W_{\text {in }}+Q_{\text {eva }}}$,

in which $Q_{c o n}$ and $Q_{\text {eva }}$ are respectively the condenser and evaporator capacity, and $W_{i n}$ is the compressor work input. They are determined as follows:

$W_{\text {in }}=\frac{\dot{m}_{r}}{\eta_{\text {comp }}} p_{\text {suc }} v_{\text {suc }}\left(\frac{\gamma}{\gamma-1}\right)\left(\left(\frac{p_{\text {dis }}}{p_{\text {suc }}}\right)^{\left(\frac{\gamma-1}{\gamma}\right)}-1\right)$,

$Q_{\text {con }}=\left(1-\exp \left(-\frac{A_{c o n} K_{c o n}}{\dot{m}_{r} C_{p, r}}\right)\right) \dot{m}_{a} C_{p, a}\left(T_{c o n}-T_{a m b}\right)$,

$Q_{\text {eva }}=\left(1-\exp \left(-\frac{A_{\text {eva }} K_{\text {eva }}}{\dot{m}_{r} C_{p, r}}\right)\right) \dot{m}_{a} C_{p, a}\left(T_{\text {in }}-T_{\text {sup }}\right)$, where $\eta_{\text {comp }}$ is the compressor efficiency, $\nu_{\text {suc }}$ is the specific volume of the refrigerant at the compressor inlet, $p_{\text {suc }}$ and $p_{\text {dis }}$ are respectively the compressor suction and discharge pressure, $A_{\text {eva }}$ and $K_{\text {eva }}$ are respectively the evaporator coil area and heat transfer coefficient, and $\gamma$ is the polytropic index of the refrigerant vapor.

The energy balance principle for the immersed coil inside the storage tank and rotary compressor is described by the following state equations:

$\frac{d T_{\text {wst }}}{d t}=\frac{\left(a_{1}+a_{2}\left(T_{\text {comp }}-T_{\text {wst }}\right)\right) a_{4}}{1-\exp \left(-\frac{A_{\text {con }} K_{c o n}}{\dot{m}_{r} C_{p, r}}\right)}+\frac{\exp \left(-\frac{A_{\text {eva }} K_{\text {eva }}}{\dot{m}_{r} C_{p, r}}\right)\left(a_{3}+b \dot{m}_{r}\right)}{1-\exp \left(-\frac{A_{c o n} K_{c o n}}{\dot{m}_{r} C_{p, r}}\right)}$,

$\frac{d T_{\text {comp }}}{d t}=\frac{\left(\frac{\dot{m}_{\text {res }}}{\dot{m}_{r}}\right)\left(a_{1}+a_{2}\left(T_{\text {comp }}-T_{\text {wst }}\right)\right) \exp \left(-\frac{A_{\text {con }} K_{\text {con }}}{\dot{m}_{r} C_{p, r}}\right)}{\left[1-\exp \left(-\frac{A_{\text {con }} K_{\text {con }}}{\dot{m}_{r} C_{p, r}}\right)\right]}+\frac{a_{3}+b \dot{m}_{r}}{\left[1-\exp \left(-\frac{A_{\text {con }} K_{\text {con }}}{\dot{m}_{r} C_{p, r}}\right)\right]}$,

where

$a_{1}=\left[\frac{A_{c o l} I \tau_{s} \alpha_{s}}{M_{w} C_{p, w}}+\frac{A_{t} K_{t}}{M_{w} C_{p, w}}\left(T_{a m b}-T_{w}\right)\right]\left(1-\exp \left(-\frac{A_{h x} K_{h x}}{\dot{m} C_{p, r}}\right)\right)$,

$a_{2}=\frac{\dot{m}_{r} C_{p, r}}{M_{w} C_{p, w}}\left(1-\exp \left(-\frac{A_{h x} K_{h x}}{\dot{m}_{r} C_{p, r}}\right)\right)$

$a_{3}=\frac{d T_{i n}}{d t}\left(1-\exp \left(-\frac{A_{e v a} K_{e v a}}{\dot{m}_{r} C_{p, r}}\right)\right)$

$a_{4}=1-\exp \left(-\frac{A_{c o n} K_{c o n}}{\dot{m}_{r} C_{p, r}}\right)-\frac{\dot{m}_{r e s}}{\dot{m}_{r}} \exp \left(-\frac{A_{\text {eva }} K_{\text {eva }}}{\dot{m}_{r} C_{p, r}}-\frac{A_{\text {con }} K_{c o n}}{\dot{m}_{r} C_{p, r}}\right)$,

$b=\frac{\dot{m}_{r e l}}{\dot{m}_{r}}\left[1-\exp \left(-\frac{A_{c o n} K_{c o n}}{\dot{m}_{r} C_{p, r}}-\frac{A_{\text {eva }} K_{\text {eva }}}{\dot{m}_{r} C_{p, r}}\right)\right]+\frac{\dot{m}_{r e s}}{\dot{m}_{r}} \exp \left(-\frac{A_{c o n} K_{c o n}}{\dot{m}_{r} C_{p, r}}\right)$, 
in which $A_{h x}$ and $K_{h x}$ are respectively the tank immersed coil area and heat transfer coefficient, $M_{w}$ and $C_{p, w}$ are respectively the water mass and heat capacity, $A_{t}$ and $K_{t}$ are respectively the storage tank area and heat transfer coefficient, $\alpha_{s}$ and $\tau_{s}$ are respectively the vacuum collector absorptance and transmittance, $I$ is the total solar radiation intensity, and $A_{\text {col }}$ is the solar collector area.

Now, substituting (6) and (7) into (1) yields the third state equation,

$$
\begin{aligned}
\frac{d T_{r l c}}{d t}= & a_{5}+\frac{\left(a_{1}+a_{2}\left(T_{\text {comp }}-T_{\text {wst }}\right)\right) a_{6} \frac{\dot{m}_{\text {rel }}}{\dot{m}_{r}}\left(a_{3}+b \dot{m}_{r}\right)}{\left[1-\exp \left(-\frac{A_{\text {con }} K_{\text {con }}}{\dot{m}_{r} C_{p, r}}\right)\right]} \\
& -\frac{\left(\frac{\dot{m}_{\text {res }}}{\dot{m}_{r}}\right)^{2} \exp \left(-\frac{A_{\text {eva }} K_{\text {eva }}}{\dot{m}_{r} C_{p, r}}-\frac{A_{\text {con }} K_{\text {con }}}{\dot{m}_{r} C_{p, r}}\right)}{\left[1-\exp \left(-\frac{A_{\text {con }} K_{\text {con }}}{\dot{m}_{r} C_{p, r}}\right)\right]}+\beta \dot{m}_{a}
\end{aligned}
$$

where the remaining coefficients are defined as

$$
a_{5}=\frac{d T_{a m b}}{d t}\left(1-\exp \left(-\frac{A_{c o n} K_{c o n}}{\dot{m}_{r} C_{p, r}}\right)\right) \text {, }
$$

$$
a_{6}=\frac{\dot{m}_{r e s}}{\dot{m}_{r}}\left(1-\frac{\dot{m}_{r e s}}{\dot{m}_{r}} \exp \left(-\frac{A_{\text {con }} K_{\text {con }}}{\dot{m}_{r} C_{p, r}}\right)\right) \text {. }
$$

\section{Control design}

The state Eqs. (6-8) are obtained by assuming isentropic operations of the compressor and assigning the system state variables as the temperatures of the refrigerant when leaving the condenser $\left(T_{r l c}\right)$, leaving the water storage tank $\left(T_{\text {wst }}\right)$, and leaving the compressor $\left(T_{\text {comp }}\right)$. The control signal comprises the currents applied to the in-line solenoid valve $\left(u_{1}\right)$ and to the condenser fan $\left(u_{2}\right)$, and the system output is the temperature of the refrigerant leaving the condenser and the compressor. The original nonlinear non-affine model obtained from Eqs. (8), (6) and (7) can be linearized around operational points of the system during each iteration interval and expressed in the form:

$\dot{x}=A x+B u \quad, \quad y=C x$

where the state vector is $x=\left[T_{\text {rlc }} T_{\text {wst }} T_{\text {comp }}\right]^{T}, u=\left[u_{1} u_{2}\right]^{T}$ is the control input vector, and $y=\left[T_{r l c} T_{\text {comp }}\right]^{T}$ is the output vector. The system matrices are given by:

$A=\left[\begin{array}{lll}0 & a_{12} & -a_{12} \\ 0 & a_{22} & -a_{22} \\ 0 & a_{32} & -a_{32}\end{array}\right], \quad B=\left[\begin{array}{cc}b_{11} & b_{12} \\ b_{21} & 0 \\ b_{31} & 0\end{array}\right], \quad C=\left[\begin{array}{lll}1 & 0 & 0 \\ 0 & 0 & 1\end{array}\right]$

where

$$
a_{12}=-\frac{a_{6} a_{2}}{1-\exp \left(-\frac{A_{c o n} K_{c o n}}{\dot{m}_{r} C_{p, r}}\right)}, a_{22}=-\frac{a_{4} a_{2}}{1-\exp \left(-\frac{A_{c o n} K_{c o n}}{\dot{m}_{r} C_{p, r}}\right)},
$$

$a_{32}=-\frac{a_{2}\left(\frac{\dot{m}_{\text {res }}}{\dot{m}_{r}}\right) \exp \left(-\frac{A_{\text {con }} K_{\text {con }}}{\dot{m}_{r} C_{p, r}}\right)}{1-\exp \left(-\frac{A_{\text {con }} K_{\text {con }}}{\dot{m}_{r} C_{p, r}}\right)}, b_{11}=\frac{\left(a_{1}+a_{2}\left(T_{\text {comp }}-T_{\text {wst }}\right)\right) a_{6} \frac{\dot{m}_{\text {rel }}}{\dot{m}_{\text {res }}+\dot{m}_{\text {rel }}} b k_{1}}{1-\exp \left(-\frac{A_{\text {con }} K_{\text {con }}}{\dot{m}_{r} C_{p, r}}\right)}$,

$$
b_{12}=k_{2} \beta, \quad b_{21}=-\frac{k_{1} b \exp \left(-\frac{A_{\text {eva }} K_{\text {eva }}}{\dot{m}_{r} C_{p, r}}\right)}{1-\exp \left(-\frac{A_{\text {con }} K_{\text {con }}}{\dot{m}_{r} C_{p, r}}\right)}, \quad b_{31}=-\frac{k_{1} b}{1-\exp \left(-\frac{A_{\text {con }} K_{\text {con }}}{\dot{m}_{r} C_{p, r}}\right)},
$$

in which $k_{1}$ and $k_{2}$ are coefficients of the relationships between the mass flow rate of the refrigerant and the air flow rate with respect to the electric currents applied to the control valve and the condenser fan.

An optimal strategy is developed to control the temperatures of the refrigerant leaving the condenser, leaving the compressor and leaving the storage tank by adjusting the mass flow rate of the refrigerant and the air flow rate at the condenser outlet via the proportional valve in the discharge line and the speed of the condenser fan, respectively. For the control design, the following performance index is used:

$J=\int_{0}^{\infty}\left(e^{T} Q e+u^{T} R u\right) d t$

where $e(t)=x(t)-x_{\text {ref }}(t)$ is the control tracking error, in which the reference $x_{\text {ref }}(t)$ is the set-point generated by using a sequential quadratic programming (SQP) optimization approach [24], $Q=Q^{T}>0$ and $R=$ $R^{T}>0$ are respectively the positive definite matrices for state and control penalty to be selected. The purpose is to construct a linear statefeedback controller of the form $u(t)=-K e(t)$ that minimizes the performance index J. For that, the commonly-used LQR control law is obtained as:

$u(t)=-R^{-1} B^{T} P e(t)=-K e(t)$,

where $K=R^{-1} \mathrm{~B}^{\mathrm{T}} \mathrm{P}$ is the control gain and matrix $P>0$ is obtained by solving the following Riccati equation:

$A^{T} P+P A+Q-P B R^{-1} B^{T} P=0$.

By solving Eq. (13) for matrix $P$ at each iteration step, we can obtain the control gain $K$ for the optimal control input. The simulation has been carried out for each $20 \mathrm{~min}$ and 20 iterations were performed in total. The set-point generation for the aforementioned variables has been determined by using the sequential quadratic programming as described in [24]. Then the optimal reference $x_{\text {ref }}(t)$ together with LQR control signal was implemented in the PLC to command the in-line valve and the variable speed drive for the condenser fan to adjust the refrigerant mass flow rate and the air flow rate.

\section{Results and discussion}

\subsection{Open loop performance}

We first consider the open-loop system. Here the experimental solar hybrid DX air-cooled air conditioning system installed in a lift motor and switchboard room is used as the cooling load and for data collection. The collected experimental data and the system components are configured and assembled using a fully integrated visual interface, namely the TRNSYS simulation studio. By creating an input file, the proposed optimization algorithm was coded according to the mathematical models described in the previous section. The code is also included as a subroutine to evaluate the thermodynamic properties of the refrigerant R410A. Furthermore, the building information file is created to meet the requirements of the ANSI/ASHRAE Standard 140-2007 [25]. The heat transfer behavior of the system has been verified using the experimental data as obtained from testing [23]. The implemented experimental data on the transient tool for ambient dry-bulb temperature and relative humidity are shown in Fig. 3.

To represent comprehensively the system operations, the monitored data, embedded in the transient simulation program for the temperature profiles of the refrigerant leaving the capillary tube, direct 


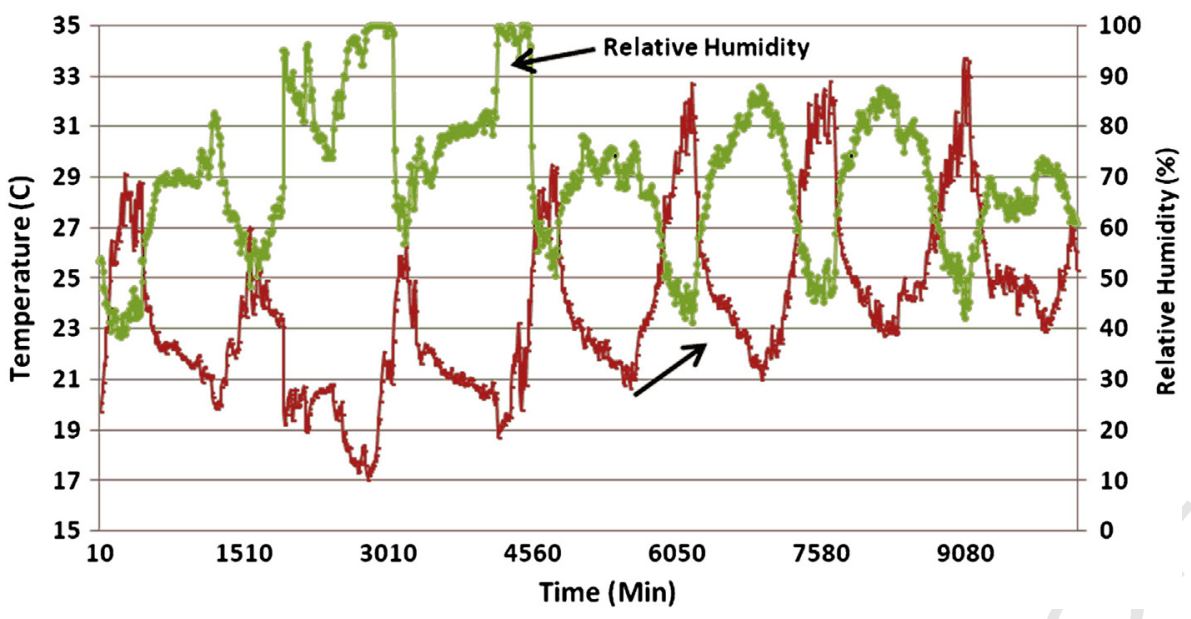

Fig. 3. Ambient condition profiles.

expansion evaporator, rotary compressor and water temperature inside the storage tank are shown respectively in Fig. 4.

\subsection{Closed-loop performance}

To predict the performance of the system throughout the summer, the cooling load is calculated prior to the simulation performed by using TRNSYS. As previously mentioned, in a DX air conditioning system, the compressor is sized to produce both the required refrigerant pressure at the expansion valve, and the temperature difference at the condenser for effective heat rejection. Consequently, a possibility appears that compressor pressures are larger than required. In our configured hybrid solar-assisted unit, the compressor is sized solely on the pressure requirement, making use of an additional heat input to account for the condenser heat rejection provided by solar collectors for most of the time.

During partial loads, when the condensing temperature is low, the refrigerant superheat leaving the compressor is normally sufficient for condenser heat rejection and so the valve opens, allowing the refrigerant to go through the new by-pass line directly to the condenser inlet. During a high cooling demand when the condensing temperature is high, the solenoid valve is closed, directing the refrigerant from the compressor into the copper coil inside the storage tank, where it acquires an amount of additional heat from the hot water. Moreover, the variable air volume condenser fan by the VSD is synchronized with the in-line valve opening and closing and adjusts the fan speed accordingly in order to increase the heat transfer rate between the ambient air and the refrigerant, and thus enhances sub-cooling at the condenser outlet. Since the nature of building cooling loads and ambient conditions is highly transient, the control valve and variable speed fan act continuously to optimize the refrigerant temperature leaving the condenser under all conditions. As a result, the reduction of refrigerant temperature leaving the condenser leads to a reduction in the refrigerant temperature entering the evaporator, enhancing the system refrigeration effect and in turn its coefficient of performance. The variations of the refrigerant temperature leaving the rotary compressor, hot water storage tank and air-cooled condenser with and without control are shown respectively in Figs. 5, 6 and 7. As expected, the temperatures of refrigerant leaving both the storage tank and condenser decrease under the proposed control scheme, with a slight change in the temperature of refrigerant leaving the storage tank. Moreover, the temperature of refrigerant leaving the compressor also decreases due to the subcooling effect, which tends to reduce the refrigerant temperature leaving the DX evaporator.

\subsection{Energy analysis}

The comparison study using simulation results indicated that the enthalpy of refrigerant entering the expansion valve with and without the new configuration is found to reduce about $8.5 \%$. Also due to a greater refrigerant effect, the refrigerant mass flow rate in the proposed system is less than that in the uncontrolled system. Furthermore, for both designs, the refrigerant vapor entering the suction inlet of the compressor is the same, which means that the specific volume of the refrigerant vapor entering the compressor does not vary for both the open-loop and the newly-developed closed-loop systems. Here, since the refrigerant flow rate can be decreased with the proposed design, its compressor

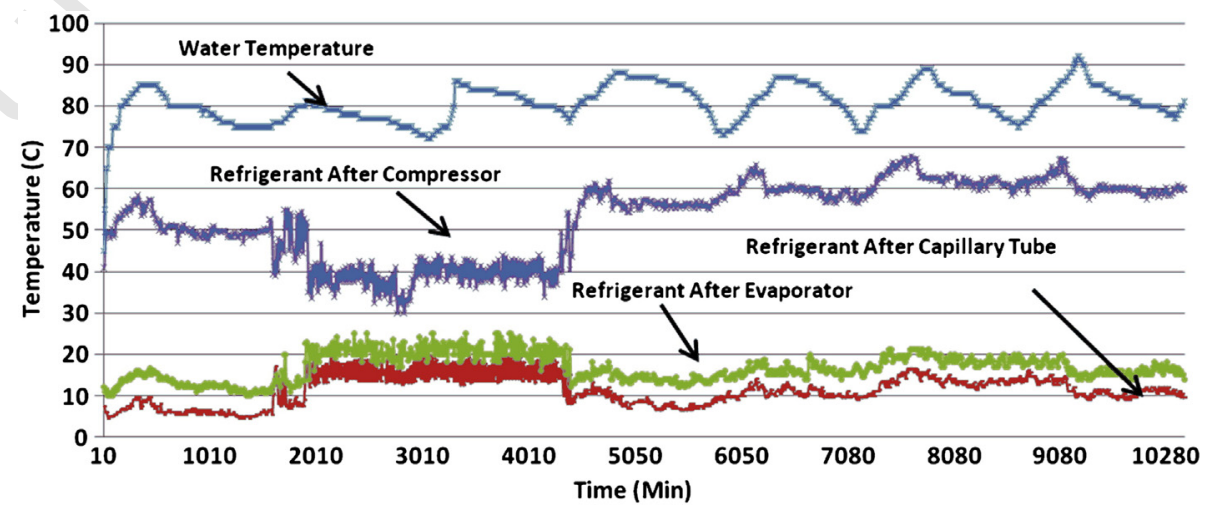

Fig. 4. Temperature profiles. 


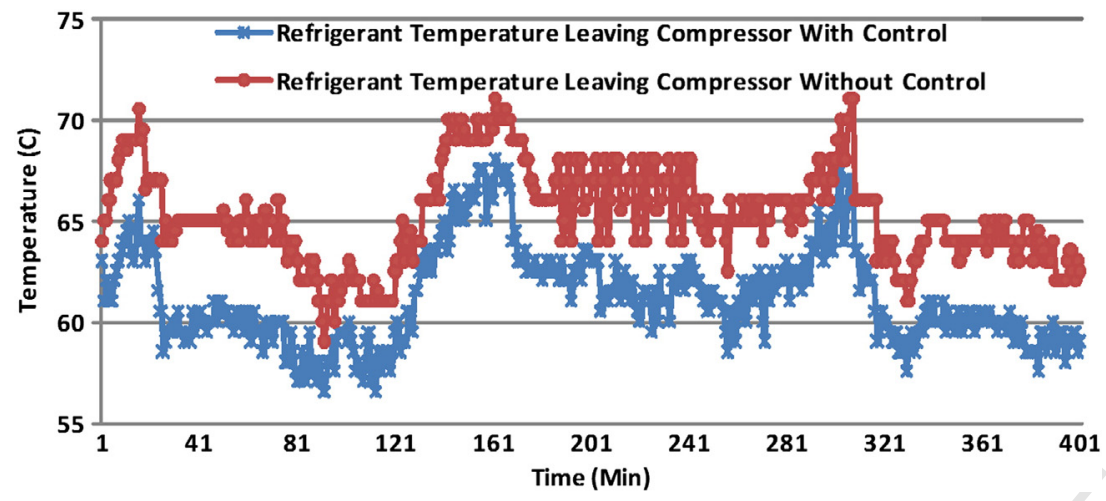

Fig. 5. Temperature of refrigerant leaving the compressor.

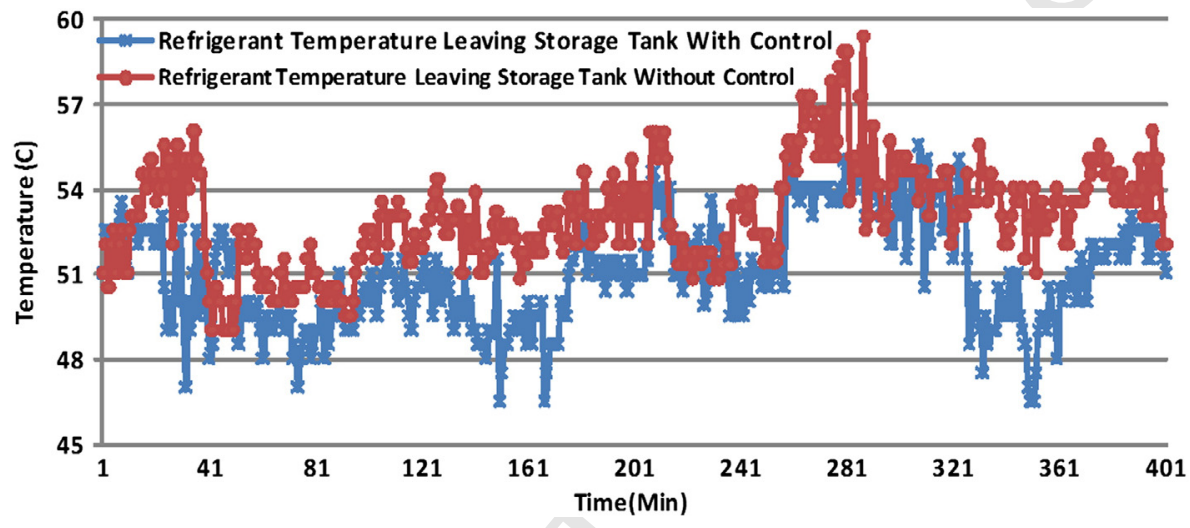

Fig. 6. Temperature of refrigerant leaving the storage tank.

must handle a smaller refrigerant vapor volume, which reduces the compressor power consumption.

This temperature reduction results in lessening the displacement volume of the compressor which, in turn, drops the compressor work. At designed steady-state conditions, the compressor power consumption for the system without control and the developed system are respectively $1.45 \mathrm{~kW}$ and $1.24 \mathrm{~kW}$, which apparently shows $14 \%$ energy savings. This energy saving potential is presented in Fig. 8 for different partial load ratios. To estimate the energy saving potential of the developed system over the summer, its energy consumption is compared with the energy consumption of the plant without control. Simulation results, shown in Fig. 9, indicate that the average power consumption by using the developed system is nearly $9.7 \%$ less than of the uncontrolled system.

\subsection{Discussion}

As can be seen from the results and energy analysis above, the compressor and air-cooled condenser fan power consumption values with control are obviously less than those without control. The average energy saving potential for the proposed approach for the compressor and condenser fan is respectively $7.1 \%$ and $2.6 \%$. Both of these reductions can result ultimately in an increase of COP, as reported in [24]. Moreover, a higher refrigeration effect causes more heat transfer in the evaporator to increase the efficiency of the DX evaporator and decrease the supply air temperature. Therefore, less supply air is required to provide the building cooling demand, resulting in a slight reduction of the supply fan power consumption. The average supply temperature of the developed system is decreased from $13.77^{\circ} \mathrm{C}$ to $11.44^{\circ} \mathrm{C}$. Additionally, the

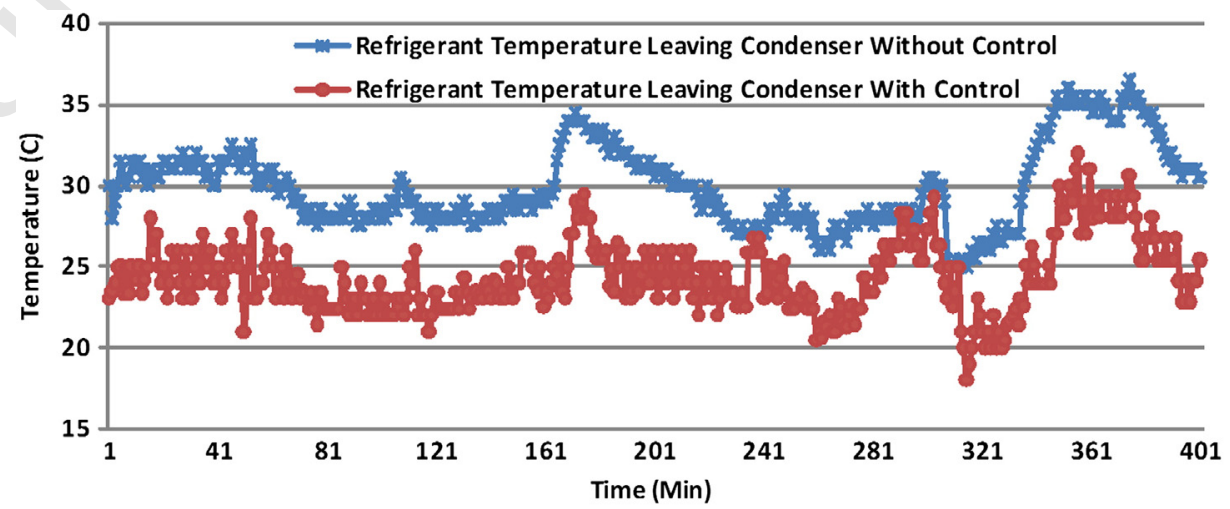

Fig. 7. Temperature of refrigerant leaving the condenser. 
Q.P. Ha, V. Vakiloroaya / Automation in Construction $x x x$ (2014) $x x x-x x x$

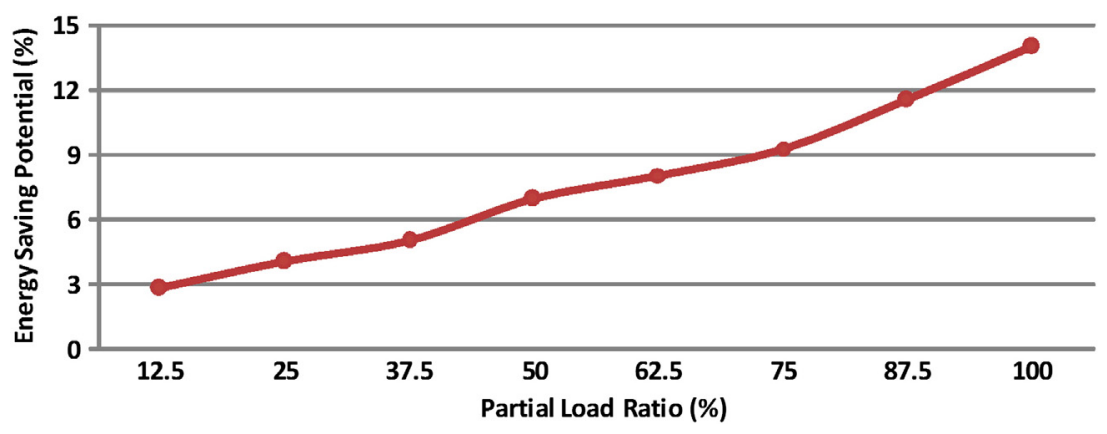

Fig. 8. Energy saving potential versus partial load ratio.

lower refrigerant enthalpy entering the evaporator tends to decrease the compressor work and in turn avoids the unnecessary heat rejection in the condenser. As a result, the compressor duty is reduced, lessening the compressor average electricity usage. However, the energy saving potential of the proposed design depends on the partial load ratio. Results demonstrate that the energy saving potential increases with the partial load ratio, as shown in Fig. 8. This is because decreasing the partial load ratio leads to lower refrigerant discharge temperature and also its temperature entering the condenser. In this situation, the system does not need much solar radiation as compared with full load conditions. Therefore, the controller would adjust the valve opening area as well as the condenser fan speed to regulate the required temperatures of refrigerant entering and leaving the condenser. The total energy usage of the whole system for each summer month can be obtained by summation of system energy consumption in each working hour. Simulation results, shown in Fig. 9, for the average energy consumption of the newly-developed system under control and the original one in summer months indicate that the power consumption of the developed system is significantly less than the power usage of the uncontrolled plant. Overall, the obtained results for the closed-loop system under control have shown that (7-14) \% electricity consumed by the compressor can be saved using the proposed system under multivariable control, as compared to the system without control. This is due to the higher refrigeration effect in the direct expansion evaporator which allows for an overall performance gain.

\section{Conclusion}

This paper has addressed the modeling and control problem of a fully-developed hybrid solar-assisted, split-system air-conditioner to target energy savings in buildings. To improve the performance of an existing solar DX air-conditioning system and allow for its closed-loop control, in our new configuration a by-pass line is implemented in the discharge line after the compressor to control the refrigerant mass flow rate via a two-way valve while a variable speed drive is connected to the air-cooled condenser to adjust the condenser fan air flow rate. A dynamic model of the system components is first derived by using mass and energy balance laws. The linear quadratic regulator technique is then applied to simultaneously control the valve and condenser fan in order to adjust the mass flow rate of the refrigerant vapor passing through a hot water storage tank and of the air flow from the condenser fan with the objective of enhancing the system performance with the proposed closed-loop optimal controller. The new design is promising for improving the system performance while fulfilling the cooling demands as well as achieving high energy efficiency.

\section{Acknowledgment}

This work is supported by the NSW Environmental Trust, project 2012/RDS/0034.

\section{References}

[1] A.A. Al-Abide, S.F. Mat, K. Sopian, M.Y. Sulaiman, C.H. Lim, A. Th, Review of thermal energy storage for air conditioning systems, Renew. Sust. Energ. Rev. 16 (2012) 5802-5819.

[2] B. Choudhury, P.K. Chatterjee, J.P. Sarkar, Review paper on solar-powered airconditioning through adsorption route, Renew. Sust. Energ. Rev. 14 (2010) 2189-2195.

[3] Department of Energy, U.S. International Energy Outlook, Energy Information Administration, 2006

[4] U. Desideri, S. Proietti, P. Sdringola, Solar-powered cooling system: technical and economic analysis on industrial refrigeration and air-conditioning applications, Appl. Energy 86 (2009) 1376-1386.

[5] International Energy Agency (IEA), Renewable for heating and cooling: untapped potential, Renewable Energy Technology Deployment, 2007.

[6] N. Li, G. Calis, B. Becerik-Gerber, Measuring and monitoring occupancy with an RFID based system for demand-driven HVAC operations, Autom. Constr. 24 (2012) 89-99.

[7] M. Qin, R. Belarbi, A. Aït-Mokhtar, F. Allard, Simulation of coupled heat and moisture transfer in air-conditioned buildings, Autom. Constr. 18 (2009) 624-631.

[8] I. Hazyuk, C. Ghiaus, D. Penhouet, Model predictive control of thermal comfort as a benchmark for controller performance, Autom. Constr. 43 (2014) 98-109.

[9] H.D. Fu, G. Pei, J. Ji, H. Long, T. Zhang, T.T. Chow, Experimental study of a photovoltaic solar-assisted heat pump/heat pipe system, Appl. Therm. Eng. 40 (2012) 343-350.

[10] C.H. Liang, X.S. Zhang, X.W. Li, X. Zhu, Study on the performance of a solar assisted air source heat pump system for building heating, Energy Build. 43 (2011) 2188-2196.

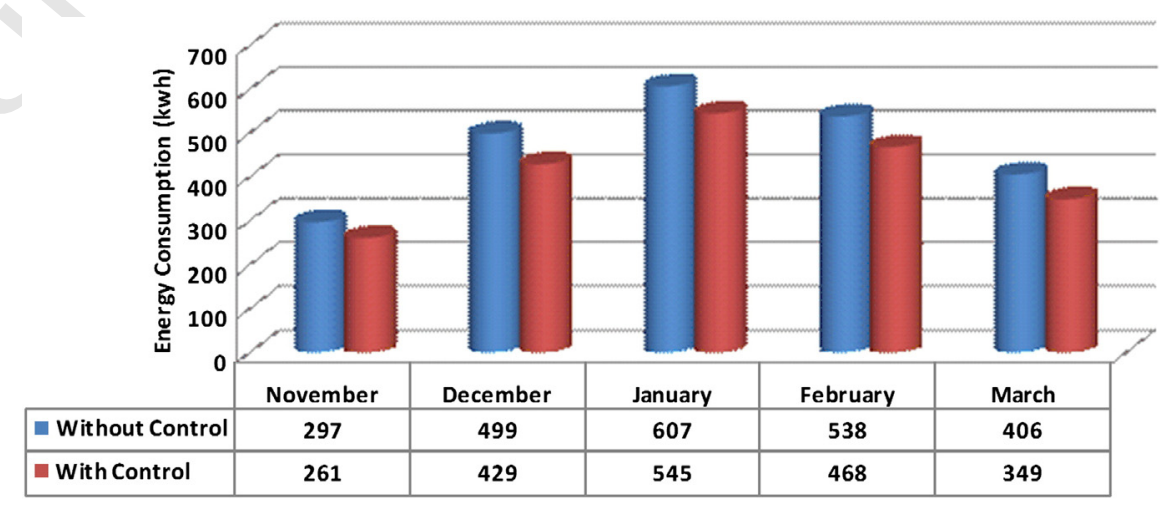

Fig. 9. Energy consumption comparison. 
[11] B.A. Jubran, H.A. Al-Hinai, Y.H. Zurigat, S. Al-Salti, Feasibility of using various photovoltaic systems for window-type air conditioning units under hot-arid climates, Renew. Energy 28 (2003) 1545-1553.

[12] M. Bilgili, Hourly simulation and performance of solar electric vapor compression refrigeration system, Sol. Energy 85 (2011) 2720-2731.

[13] S.M. Xu, X.D. Huang, R. Du, An investigation of the solar powered absorption refrigeration system with advanced energy storage technology, Sol. Energy 85 (2011) 1794-1804.

[14] Y. Sukamongkol, S. Chungpaibulpatana, B. Limmeechokchai, P. Sirpadungtham, Condenser heat recovery with a PV/T air heating collector to regenerate desiccant for reducing energy use of an air conditioning room, Energy Build. 42 (2010) 315-325.

[15] J. Guo, H.G. Shen, Modeling solar-driven ejector refrigeration system offering air conditioning for office buildings, Energy Build. 41 (2009) 175-181.

[16] D. La, Y. Dai, Y. Li, T. Ge, R. Wang, Case study and theoretical analysis of a solar driven two-stage rotary desiccant cooling system assisted by vapor compression airconditioning, Sol. Energy 85 (2011) 2997-3009.

[17] R. Daghigh, M.H. Ruslan, M.Y. Sulaiman, K. Sopian, Review of solar assisted heat pump drying systems for agricultural and marine products, Renew. Sust. Energ. Rev. 14 (2010) 2564-2579.
[18] Q. Ha, Data acquisition, monitoring and control for hybrid solar air-conditioners, Gerontechnology 11 (2012) 314.

[19] V. Vakiloroaya, Q.P. Ha, M. Skibniewski, Modeling and experimental validation of a solar-assisted direct expansion air conditioning system, Energy Build. 66 (2013) 524-536.

[20] V. Vakiloroaya, R. Ismail, Q.P. Ha, Development of a new energy-efficient hybrid solar-assisted air conditioning system, Proc. 2013 Int. Symp. Automation and Robotics in Construction, Montreal, Canada, 2013.

[21] Q.P. Ha, V. Vakiloroaya, A novel solar-assisted air conditioner system for energy savings with performance enhancement, Procedia Eng. 49 (2012) 116-123.

[22] TRNSYS software, A transient system simulation program, version 16, http://sel.me. wisc.edu/trnsys/.\&gt 2006.

[23] V. Vakiloroaya, R. Dibbs, Q.P. Ha, B. Samali, Hybrid solar air-conditioner modeling and optimal usage for energy saving and comfort enhancement, Proc. 2nd International Conference on Building Energy and Environment, Colorado, USA, 2012.

[24] V. Vakiloroaya, Q.P. Ha, B. Samali, Energy-efficient HVAC systems: simulationempirical modeling and gradient optimization, Autom. Constr. 31 (2013) 176-185.

[25] ANSI/ASHRAE Standard 140, Standard Method of Test for the Evaluation of Building Energy Analysis Computer Program, American Society of Heating, Refrigerating and Air-Conditioning, Atlanta, GA, USA, 2007. 